\title{
The extent that certain dairy farmer attitudes and behaviors are associated with farm business profitability
}

\author{
N. W. O'Leary, ${ }^{*}$ R.M. Bennett, $\dagger$ R. B. Tranter, $\dagger^{1}$ and P. J. Jones $\dagger$ \\ *Teagasc, Animal and Grassland Research and Innovation Centre, Moorepark, Co. Cork, P61 C996, Ireland \\ †School of Agriculture, Policy and Development, University of Reading, Earley Gate, Reading, RG6 6AR, United Kingdom
}

\begin{abstract}
The way in which farm managers' attitudes, personality, behavior, values, and sociodemographic characteristics influence farm business performance is, at best, only partially understood. The study reported here expands on this understanding by analyzing the attitudes and personal attributes of 80 dairy farmers in Great Britain in relation to the profitability over $3 \mathrm{yr}$ of their farm businesses. Business goals, temperament, purchasing behavior, and having a growth mindset toward the business were found to be associated with profitability. A linear regression model consisting of 5 variables related to the above was presented that predicts $34 \%$ of the observed variation in profitability. Each of these variables were questions related to the participants' personal attitudes or beliefs. Other assessed variables, such as specific husbandry behaviors or practices, or management practices and sociodemographic characteristics, did not warrant inclusion in the final model. These results uniquely contribute to understanding how the attitudes, personality, behaviors, and attributes of dairy farmers are associated with, and thus likely to influence, the profitability of their farm businesses.

Key words: farmer attitude, attributes of farmer, farmer behavior, dairy farm profitability
\end{abstract}

\section{INTRODUCTION}

Farmer attributes have received relatively little attention as drivers of farm profitability. This is especially clear when contrasted with factors such as enterprise type and farm scale. The few studies examining farmer attributes have shown that they can be predictive of profitability to a similar or greater degree. Mäkinen (2013) found that farmers' management thinking, attitudes, and beliefs were strongly predictive of dairy farm profitability. Herrmann (2016) reported that managers' commitment and discipline were moderately correlated

Received December 18, 2017.

Accepted July 29, 2018.

${ }^{1}$ Corresponding author: r.b.tranter@reading.ac.uk with farm performance. However, these few studies did not fully explore the role of attitudes and beliefs. Furthermore, no application of these insights has been reported as far as we are aware.

Using such insights, farm performance and profitability could potentially be improved. This would be a novel and potentially highly effective approach. This could be achieved during the training, or hiring of, farm managers through the measurement and management of attributes associated with farm profitability. Well-established occupational-psychology literature has demonstrated strong and consistent associations between employee (including managers) attributes and job performance (e.g., Hunter and Hunter, 1984; O'Boyle et al., 2011). Application of such insight in agriculture, however, would benefit from further research in an agricultural context. Confirming that the associations found in general occupational psychology studies exist in different groups of farmers, and how best to apply these insights effectively, would be valuable. The current paper contributes to the former by investigating the association between the attributes of farmers in Great Britain (GB) and farm profitability.

Of the range of attributes studied to date, farmer beliefs and attitudes have been found to be associated with farm profitability (Table 1). Farmer behaviors and actions have been investigated relatively more frequently than attitudes and beliefs. However, only moderate associations with farm performance have been reported for specific behaviors compared with relatively stronger associations found in the few studies examining attitudes and beliefs (Nuthall, 2010; Mäkinen, 2013; Herrmann, 2016). This implies that farmer attitudes and beliefs may be more predictive of farm profitability than specific farmer actions and behaviors.

An attitude is an expression of favor or disfavor toward a person, place, practice, or event. A belief, or conviction, is a psychological state where someone holds a specific premise to be true or not. As they are closely related concepts, attitudes and beliefs as well as objectives and goals will henceforth be referred to together as "attitudes." Behaviors relate to a person's response to particular situations or stimulus (Jones et al., 2016). 
Specific management practices (such as benchmarking) are also aggregated together with other behaviors as a subset of behaviors.

That farmers are motivated by factors besides profit is well documented (e.g., Edwards-Jones, 2006; Gasson, 1973). Attitudes relating specifically to profit have been given a range of labels, such as business orientation and profit maximizer, though they arguably describe very similar constructs. Entrepreneurial orientation, strategic thinking, and instrumental values (e.g., means to an end, making money) were found predictive of financial performance by Mäkinen (2013). These 3 measures loaded on a construct called managerial thinking that was highly predictive of profit.

Following a comprehensive literature review, the attitudes that appear advantageous for a profitable farm business from 10 selected studies are shown in Table 1. In general, viewing farming as a lucrative business combined with viewing it as a way of life appears to positively predict financial performance (e.g., Mäkinen, 2013). Encouraging farmers to embrace these attitudes or challenge contrary attitudes may thus increase farm profitability.

Other attitudes have also been linked to profitability. Herrmann (2016) found that farms run by those who placed greater value on their own leisure had smaller increases in equity over $3 \mathrm{yr}$ than those that did not. Nuthall (2010) found that those who prioritized risk reduction had more profitable farms than those that did not. Believing that farming delivers more than just food, but also public goods, was found to be associated with greater technical efficiency by Barnes (2006).

The study reported here explored whether the attitudes and behavior of farmers, as operationalized in the Theory of Planned Behavior (Ajzen, 1991), were associated with the profitability of their dairy farms in GB as measured by their farm accounts data. The sample used is not especially representative, so the objective is not to accurately estimate statistically the prevalence of attitudes and behaviors in GB dairy farmers, but to identify associations and patterns which are likely to generalize to GB dairy farmers, dairy farmers in other countries, and other GB farmers. Below, the profit measure used as a proxy for management performance, is first discussed. Then an exploratory correlation analysis of the participants' survey responses, attributes, and their associations with their farm profitability is examined. The results of a linear regression model using these variables follow, which predicts a significant proportion of the variation in farm profit of the study farms. The findings are then summarized and discussed before conclusions and recommendations based on the study's findings are presented.

\section{MATERIALS AND METHODS}

\section{The Questionnaire Used}

A questionnaire containing 83 questions was initially developed in early 2012. This was based on the find-

Table 1. A summary of the attitudes and objectives found to be associated with farm profitability derived from a literature review

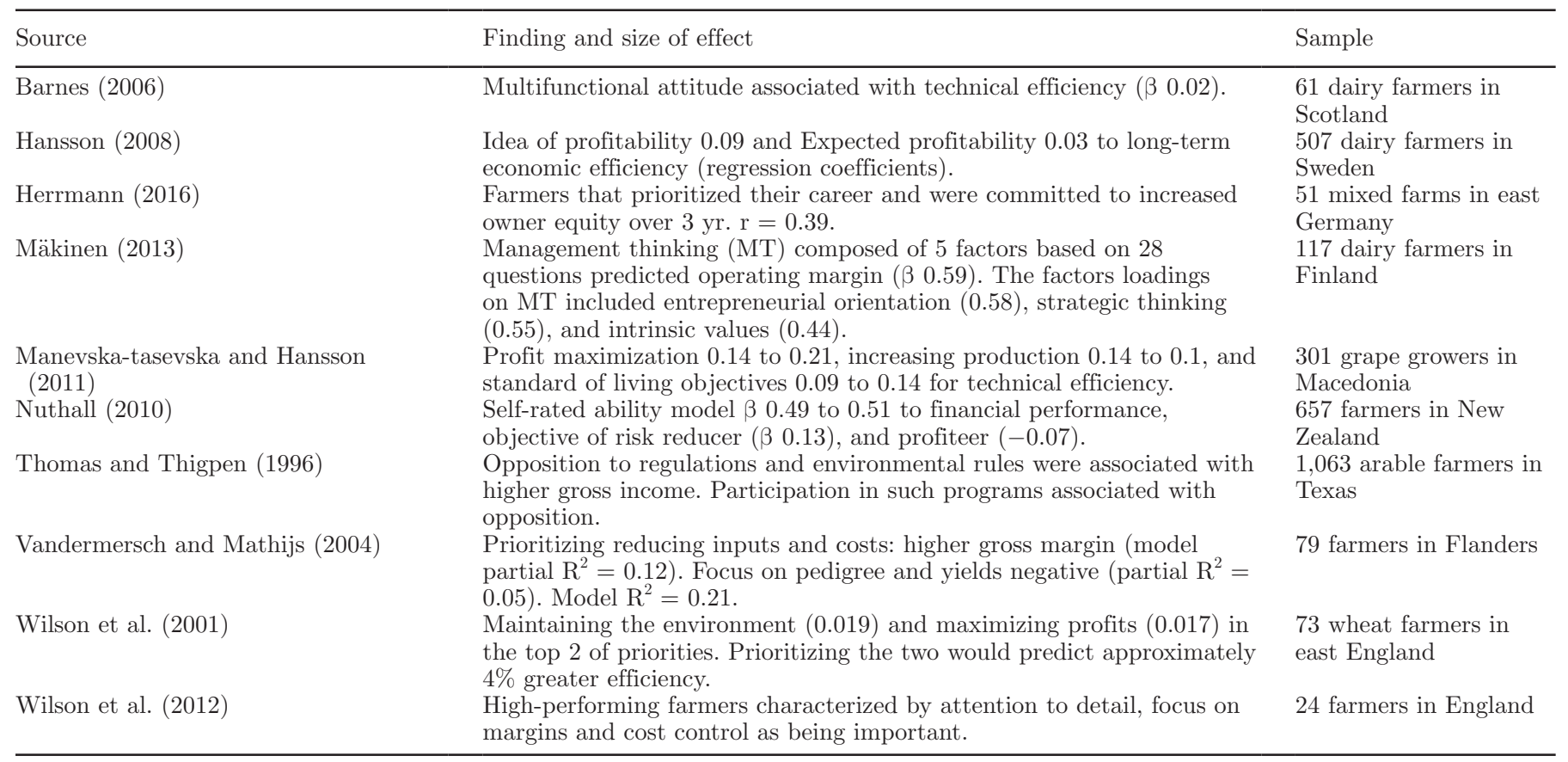


ings of a review of the literature and discussions with a group of experienced farm management consultants. The questionnaire had 5 sections with questions on farm management style, staff management practices, business goals and objectives, personal views on management, and sociodemographic characteristics of the farmer or farm manager and their farm business. The majority of the questions (59/83) consisted of propositional statements to which respondents had to indicate their level of agreement on a 5-point Likert scale, with 1 being agree strongly and 5 being disagree strongly. Each of the questions were exploratory and hypothesized to be potentially associated with farm profitability. Some themes were judged to be more likely associated with profitability were addressed by multiple questions. These were asked in different ways; for example, negatively or positively framed or assessing a closely related aspect. These could be considered as either related to attitudes or behavior constructs of the Theory of Planned Behavior framework of Ajzen (1991). Figure 1 illustrates how the study reported here investigated the role of behaviors and attitudes as potential predictors of dairy farm profitability based on the Theory of Planned Behavior framework.

Example statements or questions that related to attitudes included "Increasing turnover is essential for long-term success"; "Content cows are a major source of pride"; and "Staff entering the industry lack important skills and knowledge." Example statements or questions related to behaviors included: "I buy most of my inputs from 1 or 2 local suppliers"; and "I don't usually pay for staff training as they may leave after or I would rather do it myself."

Experienced farm management researchers (the authors and others) revised the first draft questionnaire, which was then followed by pilot testing on 4 individual farmers. The resulting final version of the questionnaire (the questionnaire is available from the corresponding author or from https://goo.gl/ZnuWUz) was then mailed to 234 dairy farmers who were clients of the business services of Promar International (Nantwich, UK; a major agrifood consultancy organization) in the spring of 2012. Following written and verbal reminders, 101 responses were elicited (a $43 \%$ response rate), 21 of which were then removed from the analysis for incompleteness. This resulted in a final sample of 80 (a $34 \%$ response rate) of those questionnaires distributed.

\section{Sample Characteristics}

The participants managed either a specialist dairy or mixed dairy farms with a herd size of milking cows between 34 and 453, a sample mean of 198 (Table 2). This was larger than the UK average of 126 at that time (DairyCo, 2013a). However, the sample was representative in other key respects. For example, mean yield per

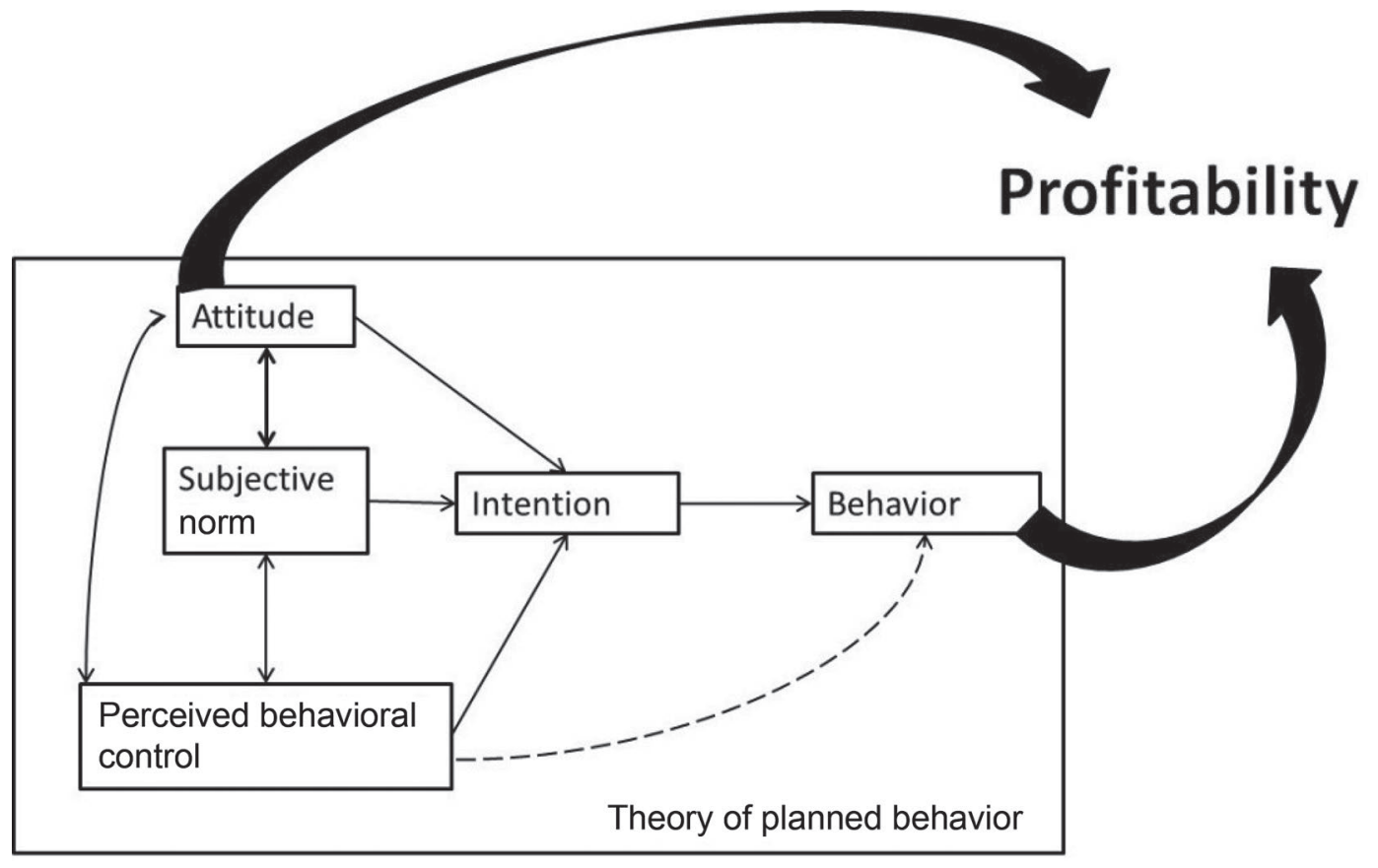

Figure 1. Diagram of the Theory of Planned Behavior adapted to illustrate the focus of this study with the 2 thick dark arrows pointing to profitability. Adapted from Ajzen (1991). 
Table 2. Summary statistics of the survey sample

\begin{tabular}{lcc}
\hline Item & Mean & $\begin{array}{c}\text { Standard } \\
\text { deviation }\end{array}$ \\
\hline Age of participant (yr) & 50.5 & 9.2 \\
Number of milking cows & 198 & 110 \\
Yield per cow (L) & 7,595 & 1,210 \\
PBRC $(£)$ & 153,459 & 89,800 \\
PBRC + wages $(£)$ & 216,050 & 114,501 \\
PBRC/turnover (\%) & 22 & 8 \\
(PBRC + wages)/turnover (\%) & 31 & 7.6 \\
\hline
\end{tabular}

${ }^{1}$ Profit before resource costs. As of Feb. 1, 2012, £1 $=\$ 1.58$.

cow was $7,595 \mathrm{~L}$, similar to the UK average of 7,604 in 2011 and 2012 (DairyCo, 2013b), and the average age of the participants was $50.5 \mathrm{yr}$ compared with the national average of 51.4 (Farm Business Survey Team, 2012). In terms of geographical spread, South Wales and Scotland were under-represented. Whereas these sample characteristics are not ideal for an exploratory study such as the one reported here, it can be described as satisfactory.

\section{Profitability as a Proxy for Farm Manager Performance}

A profit-based measure was deemed the most appropriate proxy of success or generally desirable outcomes. The measures return on assets and return on equity were considered, but discounted because necessary land valuations were not updated regularly in the farm management accounts data set used. Net farm income (NFI) was identified as being a relatively fair measure of profitability to assess the performance of a manager, as it adjusts for rent and unpaid family labor, which are generally outside managers' control in the short to medium term. However, it was not possible to calculate NFI in the study reported here, as an estimate of unpaid family labor was not collected in the data set used. Therefore, a similar measure of profitability was selected, profit before resource costs (PBRC). This is a profitability measure that does not include costs such as rent on land or finance charges on borrowed capital but does include wages paid to both family and regular hired farm staff. As rent and finance are mostly attributable to an individual farm's resource base or endowment, the everyday actions of the farmer or farm manager, at least in the short and medium term, can only have limited effect on these factors (Table 2). To see in a detailed way how PBRC is calculated, the reader should refer to the Appendix of this paper. In Table A1 is an annotated version of an example set of farm accounts is presented.

Three other measures of financial performance were also calculated. First, to avoid bias due to business size, PBRC divided by turnover was calculated. Second, PBRC was also calculated with real wages of family and regular labor added back in. Third, PBRC divided by turnover was also calculated with real recorded wages added back in. This latter measure is, in one sense, a superior measure to NFI, as only bank-reconciled figures were used and the participating farmers were not required to estimate the value of unpaid family labor, which would be likely to introduce some inaccuracy.

To minimize the effects of annual variation through factors such as unusual weather or commodity price volatility, financial performance means were calculated over 3 financial years, 2011 to 2014. The questionnaire survey that collected the attitudinal and sociodemographic data was carried out during the spring of 2012 (i.e., near the end of the first of these 3 financial years), approximately one third of the way through the financial period assessed. The financial data were collected routinely each year for the purpose of preparing farm management accounts for their clients by Promar International.

The 4 profit measures considered adjust for certain biases that might affect the apparent influence of the farm manager on profitability. Although these measures are inherently similar and closely related, they are distinct, with correlations between them ranging from 0.43 to 0.93 (Table 3 ).

The PBRC with wages added and divided by turnover was judged as the measure most indicative of desirable outcomes or success attributable to the farm manager, being independent of those variables that are outside the farmer or farm manager's control. In the results that follow, and the tables that are shown, this measure is referred to as (PBRC + wages)/turnover.

Table 3. Correlation matrix of the profit measures examined (Pearson's r)

\begin{tabular}{lcccc}
\hline Item & PBRC & PBRC + wages & PBRC/turnover & (PBRC + wages)/turnover \\
\hline PBRC & 1.00 & 0.93 & 0.65 & 0.62 \\
PBRC + wages & 0.93 & 1.00 & 0.43 & 0.58 \\
PBRC/turnover & 0.65 & 0.43 & 1.00 & 0.81 \\
(PBRC + wages)/turnover & 0.62 & 0.58 & 0.81 & 1.00 \\
\hline
\end{tabular}

${ }^{1}$ Profit before resource costs. 


\section{RESULTS}

\section{Univariate Analysis}

Statistically significant correlations of sociodemographic parameters with the financial performance measure chosen close to or below the $P<0.05$ threshold are listed in Table 4 along with mean scores and standard deviations for each response. Spearman's nonparametric correlation analysis (rho) was used. A few variables with a $P$-value greater than 0.05 are reported, as they are included in the multivariate analysis reported below.

About $10 \%$ of profitability variation can be predicted by farmers' self-reported profit-focused attitude; most respondents agreed tentatively (41\%) and a few agreed strongly (15\%), whereas $25 \%$ were neutral and $19 \%$ disagreed. By the farmers' own assessment, there is scope for the majority of their farm businesses to be more profit-orientated. The most highly correlated attitudinal variable with profit was the respondents' own assessments of whether increasing turnover is essential for long-term success.

Many of the study farmers appeared to have a negative view of continuing personal development. Several variables indicative of this view were also strongly correlated with profitability. For example, the most highly correlated of these to profitability was the reported provision of training for staff and themselves (rho = 0.29). The educational attainment level of the manager was also positively correlated, but to a lesser extent (rho $=0.21, P=0.06$ ). Specifically, a formal agricultural training qualification appears to be beneficial.

Respondent age and years of management experience were not significantly correlated with financial performance. Though slightly more profitable on average, farms managed by university graduates with agricultural degrees (18\% of the sample) were not statistically significantly more profitable than those of without agricultural degrees $(P=0.18)$. This indicates that the formal agricultural qualification is important, not necessarily the level of qualification achieved, although higher levels appear to be slightly advantageous.

Overall, $64 \%$ of respondents had some form of agricultural education beyond A levels (i.e., beyond high school, including degrees) and their businesses had $4 \%$ greater profit (or turnover) than those of people with no formal agricultural education beyond A level ( $t$-test, $P<0.001$ ). It was found that the least educated had a more negative view of discussion groups than their more-educated counterparts. Educational attainment was negatively correlated with viewing farm walks and discussion groups as essential (rho $=-0.29, P=0.01$ ). These correlations support the assertion that farm business profitability is associated with farmers' views on continuing personal development.

Eleven of the 80 farmers reported paying off loans early; their businesses were significantly less profitable than others ( $t$-test, $P=0.04$ ). Early loan repayment may be an unwise alternative to on-farm investments if one assumes reasonable levels of finance costs. Nine of the 80 respondents reported investing profits off-farm; these businesses tended to be more profitable ( $t$-test, $P$ $=0.07)$.

The literature review found that age, decisionmaking processes, and locus of control were unlikely to be predictive of financial performance; this finding is supported by the low nonsignificant correlations with profitability that we observed. The correlations did not approach the $P$-value of 0.05 or less significant threshold chosen for presentation in this paper. For example, locus of control proved to be not correlated with profitability, with a Spearman's rho of just 0.12 $(P=0.30)$. No correlation was found between hours worked and financial performance. The same was true for general self-rated management ability on a scale of 1 to 10 , indicating that effort in the form of hours worked and general self-rated management ability are not predictive of financial performance. All the questions in the questionnaire were assessed for associations with profitability and, if they were not included in the above section on correlations with performance, or presented in Table 4, they were not significantly associated with profitability at the $P<0.05$ level.

\section{Multivariate Analysis}

To assess the relative importance of the variables correlated with farm profitability, multivariate linear regression was performed. The variables with the largest correlations with financial performance (Table 4) were included in an initial model. Variables were progressively eliminated using a stepwise approach (Vandermersch and Mathijs, 2004) based on variable $P$-values in the various models and the model Akaike information criterion values. In this way, variables were eliminated from the model until all remaining variables were significant.

The final model is presented in Table 5 and contains only 5 variables. The variable with the largest univariate association with profitability, "viewing increasing turnover as essential to success," was removed from the analysis. This was because it was deemed likely to have an endogenous relationship with the chosen dependent variable. Expressing ambition to expand should, however, be considered a positive predictor of farm outcomes and was associated positively - though 
O'LEARY ET AL.

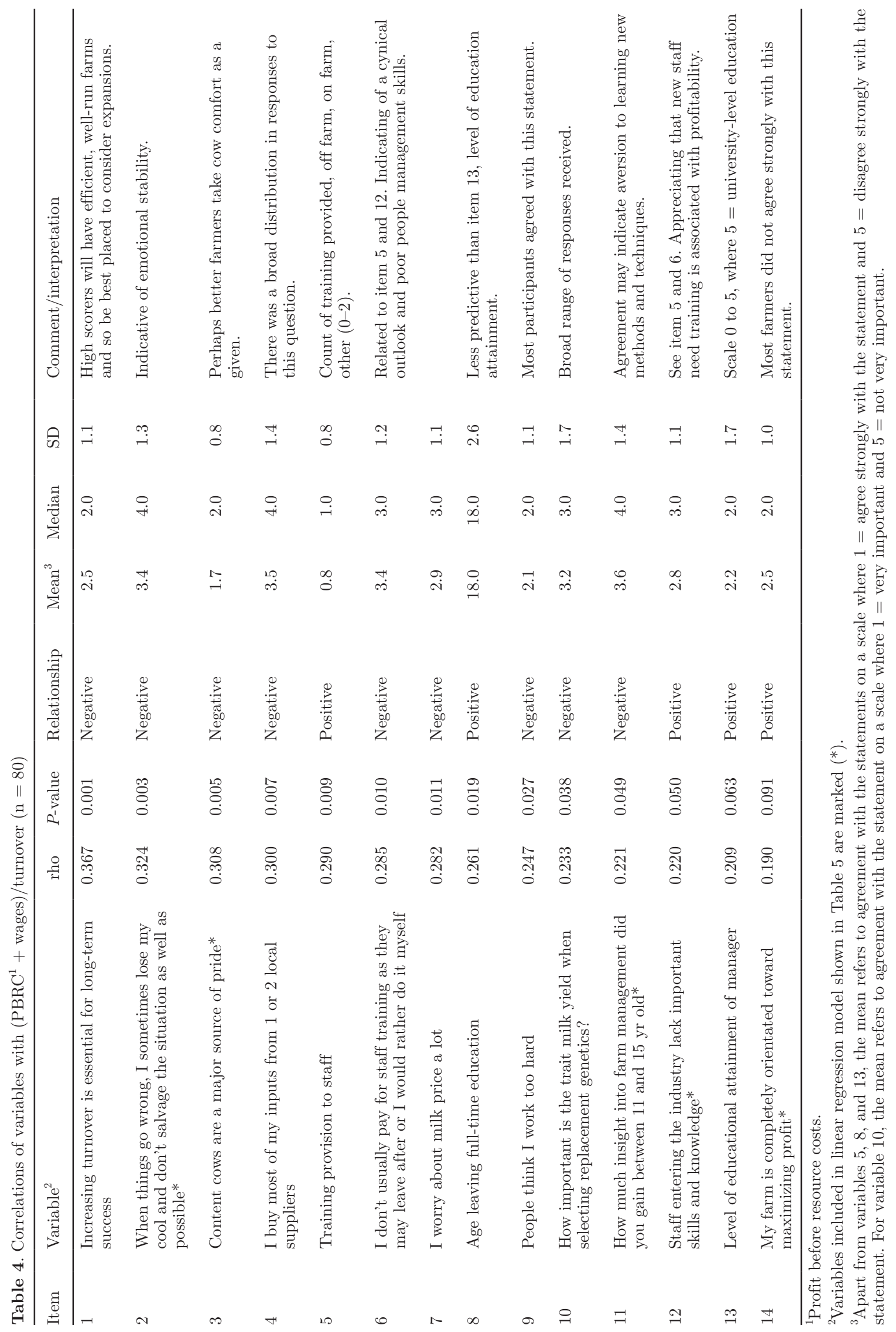


Table 5. Linear regression model explaining $\left(\mathrm{PBRC}^{1}+\right.$ wages $) /$ turnover $\left[\mathrm{R}^{2}=0.34\right.$ (adjusted $\left.\left.=0.30\right)\right]$

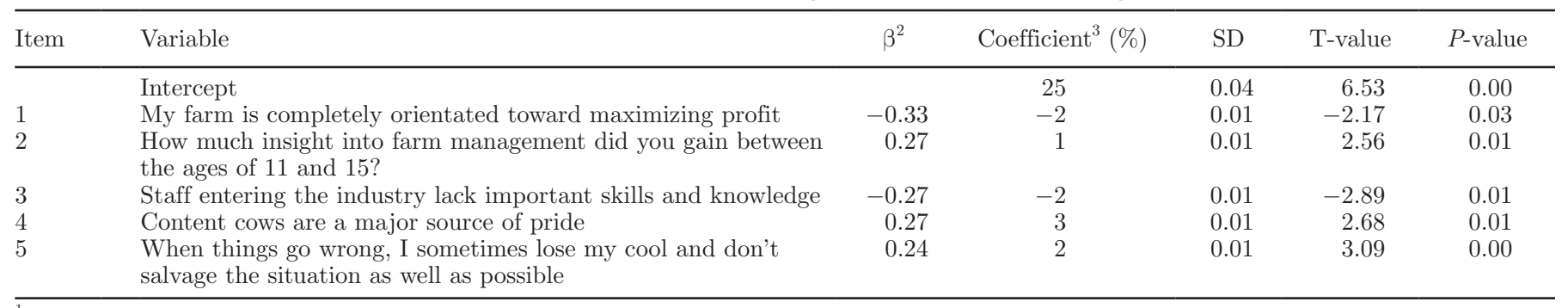

${ }^{1}$ Profit before resource costs.

${ }^{2} \beta=$ standardized coefficient.

${ }^{3}$ The coefficient can be interpreted as the percent change in profitability associated with a 1-point change in the independent variable (question response).

not always at the $P<0.05$ threshold - with all 4 PBRC profit variables. The associations were strong where turnover was the denominator. This finding supports the interpretation that the chosen dependent variable's large association with this variable was partially spurious from the perspective of assessing manager performance, in general.

Most of the model variables were independent of each other, with the exception of variables 4 and 5 (rho $=$ $0.27, P=0.01$ ), which both relate to emotions (pride and anger) in management. The less-profitable businesses tended to have managers who reported these emotions as being more important.

During the model-testing phase, all the variables were tested for interactions with each other but were found to be nonsignificant. The variance inflation factor calculated for the model of 1.5 indicated multicollinearity was not a major concern. A QQ plot of the model residuals indicated the independent variables were fairly normally distributed. This indicated a linear regression model was appropriate in this context. The coefficient of determination value of 0.34 for the model indicated that $34 \%$ of the variation in the profit measure was explained or predicted by the responses to these 5 questions. However, as cross-validation was not performed, it is likely that this model is somewhat over-fitted; therefore, validation of these findings in novel samples of farmers would be advantageous.

The same variables were included in models of each of the 3 other PBRC profitability measures, with 29, 31, and $29 \%$ of the variation explained for PBRC, PBRC/ turnover, and PBRC plus wages, respectively (see Table 6 ). Large changes in profit were also predicted for the 3 other measures for variation in all 5 question responses (variables). For example, £33,575 more PBRC (£1 $=\$ 1.58$, as of Feb. 1, 2012) was predicted for each point of agreement on a 5-point scale with the statement that respondents' farm business is completely profit-oriented. This variable is the most predictive of profitability in the model based on standardized coefficients. The focus on profit is, presumably, primarily at the discretion of the manager, but it could be partially endogenous, with less-profitable farmers stating that they do not prioritize profit because they know they are not very profitable. The second most important variable was the self-assessment of management insight gained during teenage years. This variable was found to be negatively associated with profitability; that is, the more that respondents affirmed that they learned a great deal about farming during their teenage years, the lower the profitability of their businesses. This variable and the remaining 4 model variables are discussed in more detail below.

\section{DISCUSSION}

Our study identified certain farmer attitudes and, to a lesser extent, behaviors that are associated with the profitability of their dairy farm businesses. The variables included in the linear model were nearly all attitudes, with only 1 behavior being included ("When things go wrong, I sometimes lose my cool and don't salvage the situation as well as possible").

Foremost among behaviors associated with profitability was respondents' agreement with the statement that their farm business is profit-oriented. Those not agreeing with this statement strongly had much less profitable businesses. As the sample used in our study included farm managers engaging in a farm accounting service, these figures are likely to be biased toward more profit-focused farmers and, as shown by average herd size values, were biased toward larger enterprises. Many might also have been engaging a farm consultant from the same company, further highlighting a particular commercial focus; this will likely also influence many other responses to the survey questionnaire. However, the primary objective of our study was not to identify prevalence of attitudes and behaviors in dairy farmers 
Table 6. Change in profit measure predicted for each positive change in rank score for the 5 regression variables

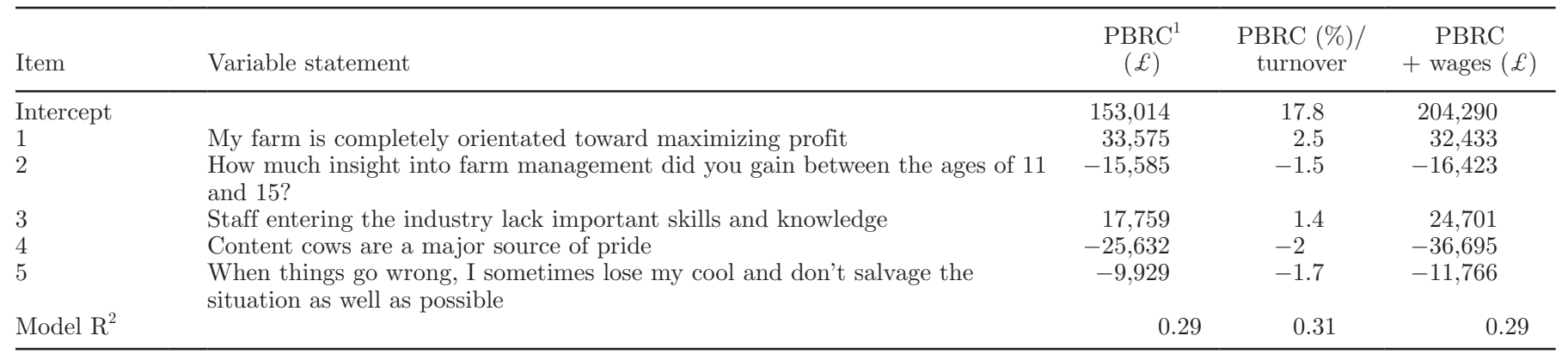

${ }^{1}$ Profit before resource costs. As of Feb. 1, 2012, £1 $=\$ 1.58$.

in GB, but to identify associations and patterns likely to generalize to dairy farmers in other countries and, perhaps, non dairy farmers.

Variable 2 and variable 3 of the linear regression model results related to participants' attitudes toward self-learning and staff skills and knowledge, respectively (Table 5). Those who indicated that they gained a great deal of management insight during their teenage years were found to have less-profitable businesses. This was counter to the hypothesized direction of association when we formed the question. As a post hoc rationalization of this finding, we assumed that those who indicated that they learned a great deal during their early teens, it is likely that they learned less in the period that followed. Similarly, those that think novice staff do not require training and development had less-profitable businesses. Those who learned a great deal in their teens did not think novice staff need training and appeared to underestimate the value of training and skills. Together with the correlations with training provision by the farm business and the educational attainment of the farmers and farm managers, themselves, this indicates a broader view toward continuing personal development. This view most likely relates to having a growth or fixed view of human ability.

Having a growth mindset entails believing that people can change and develop their behavior over time, particularly when they devote a concerted effort to learn and apply more effective strategies for task performance. A fixed mindset entails believing personal attributes constitute a largely stable entity that tends to not change much over time (Heslin and Vandewalle, 2008).

Two other statements that were posed were more directly related to a growth mindset. These included "Management is a skill that can be honed and improved," and "Good managers are born, not trained." Responses to both questions did not correlate with profitability, perhaps due to a social desirability bias influencing responses. Questions relating to training provision and perceptions of learning were, perhaps, not as affected by a social desirability bias, as they indirectly relate to a growth mindset. Social desirability bias occurs when participants do not respond accurately, intentionally or unintentionally, to maintain appearances and reduce the risk of embarrassment by answering how they think they should (Fischer, 1993). This could be a potential drawback of the self-reported assessment of attitudes and behavior used in our study. Nevertheless, this provides contrary evidence to our assertion that a farmer's growth mindset, and view of continuing personal development, are associated with profitability. In aggregate, however, it appears clear that the growth mindset and, in particular, viewing continuing personal development as being valuable are important.

Interventions to increase a growth mindset have been shown to affect self-rated performance in some contexts (Visser, 2013). In addition, Heslin and Vandewalle (2008) illustrated that a growth mindset can be created among managers and that the effects were durable. In their study, increased growth mindset remained 6 wk after the intervention. Therefore, it is possible that farmers and farm managers with a fixed mindset could, thus, be coached to have more of a growth mindset and potentially improve the financial performance of their farm businesses.

A growth mindset has been shown to be important in several contexts (Heslin and Vandewalle, 2011). However, the study discussed here is one of the first to find that profitability is associated with a manager's growth mindset-related variables. The current findings, thus, have potential significance outside agriculture (Heslin and Vandewalle, 2008; Mischel, 2014).

Variable 4 examined whether participants viewed cow comfort as a source of pride, and agreement was negatively associated with profitability. This was counter to the hypothesized direction of association when we designed the question. One potential interpretation is that more profitable managers view cow comfort as 
assumed, not an achievement to take pride in. This interpretation is consistent with the findings of Vandermersch and Mathijs (2004) and Braun (2012).

Finally, variable 5 of the linear regression model relates to behavior in a specific circumstance that is indicative of personality and temperament. How a farmer reported responding when things go wrong and, if they have a tendency to "lose their cool" was associated with profitability. Those that indicated they did not always salvage situations and who sometimes lose their cool were found to manage less-profitable businesses. Variables 4 and 5 indicate that rational, emotionally stable, and conscientious farmers are likely to have more-profitable farm businesses.

Not included in the linear regression model, but highlighted in the univariate analysis, was the strong association between an agricultural education and profitability and the lack of an association with self-rated ability. Education was generally positive, and Läpple et al. (2013) found that those with the least education were the ones most likely to benefit from discussion group participation. However, those with less education were found to have a more negative view of the usefulness of discussion groups in our study.

The fact that farmers' self-assessment of their own ability was not correlated with outcomes was somewhat surprising given the results reported by Nuthall (2010), where a strong relationship was found. In that study, however, farmers were asked to rate their ability in 5 specific areas, whereas our study only asked for a more general self-assessment of ability. Self-assessment is, thus, likely to be associated with performance as long as the measure is sufficiently detailed and granular.

Our findings will be of significant value to 4 stakeholder groups, including future and current dairy farmers, farm advisors and educators, recruiters of dairy farm managers, and third-party investors in farm land and businesses, such as banks. The research presented here can, perhaps, have a more immediate effect in an educational context; for example, agricultural courses could include a focus on the topics identified. Students could complete assessments that estimate how they would perform as farm managers based on their responses to the questions reported here associated with profitability. Similarly, farm advisors could identify where farmers' attitudes and behaviors differ from those most associated with farm business profitability and assess if changes would be appropriate.

Recruiters of farm staff and farm managers could assess candidates' attitudes to see how consistent they are with those found here to be most associated with profitable farming. With large applicant pools, an algorithm could help filter applicants and guide close final decisions. Potential farmland investors or creditors could also gain insight into the prospects of dairy farmers with a similar approach.

This study only examined dairy farmers in GB and repeating the study for farmers with other types of enterprises and from other countries would be of value. Including other farmer attributes, such as personality and general cognitive ability, is also likely to increase the proportion of variation in outcomes explained significantly.

Farmers have a central role in food security, environmental management, and the wider rural economy. Thus, it is no longer tenable that research into farm profitability generally treats farmers as a black box to be worked around. All promising avenues to improve farm performance should be pursued. Developing and managing farm managers with insights, such as those outlined here, could be an effective and relatively inexpensive way to increase agricultural sustainability. Given the large effects observed in the study reported here, using the insights from the current study might also offer significant rates of return on such investment.

\section{CONCLUSIONS}

The importance of farmer attributes in predicting farm profitability has been affirmed here, with a large and significant proportion of variation in farm profitability predicted independent of technical variables, such as scale, land type, and region. In addition, our findings are coherent and offer practical insights to farm management that are, mostly, not counter to expectations. However, the scale of the associations found is, perhaps, larger than might have been expected. In our study, certain attitudes and, to a lesser extent, behaviors of farmers and farm managers were found to predict farm profitability. These were, in descending order of importance, having a profit objective, having a growth mindset, and indicators of conscientiousness and emotional stability. Several other variables were also correlated with farm business profitability but did not warrant inclusion in a final multivariate regression model examining other variables.

\section{ACKNOWLEDGMENTS}

The authors thank the participating farmers, Andrew Thompson and Tim Harper of Promar International (Nantwich, UK) for facilitating this study. The project reported received support from the Knowledge Transfer Partnership's programme, overseen by Innovate UK (Swindon), the UK's innovation agency, which is supported by 16 other public sector funding organizations. 


\section{O'LEARY ET AL.}

\section{REFERENCES}

Ajzen, I. 1991. The theory of planned behaviour. Organ. Behav. Hum. Decis. Process. 50:179-211.

Barnes, A. P. 2006. Does multi-functionality affect technical efficiency? A non-parametric analysis of the Scottish dairy industry. J. Environ. Manage. 80:287-294.

Braun, C. M. 2012. An analysis of how dairy farmers divide their time among twelve key management areas and farm profitability. PhD Thesis. Department of Agriculture, Cornell Univ., Ithaca, NY.

DairyCo. 2013a. Average herd size. Accessed Sep. 6, 2018. https:// dairy.ahdb.org.uk/resources-library/market-information/farming -data/average-herd-size/.

DairyCo. 2013b. Average milk yield. Accessed Sep. 6, 2018. https:/ /dairy.ahdb.org.uk/market-information/farming-data/milk-yield/ average-milk-yield/.

Edwards-Jones, G. 2006. Modelling farmer decision-making: Concepts, progress and challenges. Anim. Sci. 82:783.

Farm Business Survey Team. 2012. Data Builder User Guide. Rural Business Research. Accessed Aug. 24, 2012. http:// farmbusinesssurvey.co.uk/DataBuilder/Default.aspx?module= UGExampleFarmersAgeType.

Fischer, R. J. 1993. Social desirability bias and the validity of indirect questioning. J. Consum. Res. 20:303-315.

Gasson, R. 1973. Goals and values of farmers. J. Agric. Econ. 24:521537.

Hansson, H. 2008. How can farmer managerial capacity contribute to improved farm performance? A study of dairy farms in Sweden. Acta. Agric. Scand. C Food Econ. 5:44-61.

Herrmann, E. F. F. 2016. An investigation into the relationship between the personality characteristics of managers and their business performance- The case of cooperative farms in former East Germany. PhD Thesis. School of Agriculture, Policy, and Development. Univ. of Reading, Reading, United Kingdom.

Heslin, P. A., and D. Vandewalle. 2008. Managers' implicit assumptions about personnel. Curr. Dir. Psychol. Sci. 17:219-223.

Heslin, P. A., and D. Vandewalle. 2011. Performance appraisal procedural justice: The role of a manager's implicit person theory. J. Manage. 37:1694-1718.

Hunter, J. E., and R. F. Hunter. 1984. Validity and utility of alternative predictors of job performance. Psychol. Bull. 96:72-98.

Jones, P. J., J. Sok, R. B. Tranter, I. Blanco-Penedo, N. Fall, C Fourichon, H. Hogeveen, M. C. Krieger, and A. Sundrum. 2016. Assessing, and understanding, European organic dairy farmers' intentions to improve herd health. Prev. Vet. Med. 133:84-96.

Läpple, D., T. Hennessy, and C. Newman. 2013. Quantifying the economic return to participatory extension programmes in Ireland: An endogenous switching regression analysis. J. Agric. Econ. 64:467-482.

Mäkinen, H. 2013. Farmers' managerial thinking and management process effectiveness as factors of financial success on Finnish dairy farms. Agric. Food Sci. 22:452-465.

Manevska-tasevska, G., and H. Hansson. 2011. Does managerial behavior determine farm technical efficiency? A case of grape production in an economy in transition. Manage. Decis. Econ. 412:399-412.

Mischel, W. 2014. The Marshmallow Test: Mastering Self-Control. Back Bay Books, New York.

Nuthall, P. L. 2010. Should farmers' locus of control be used in extension? J. Agric. Educ. Ext. 16:281-296.
O'Boyle, E., R. H. Humphrey, J. M. Pollack, T. Hawver, and P. A. Story. 2011. The relation between emotional intelligence and job performance: A meta-analysis. J. Organ. Behav. 32:788-818.

Thomas, B. J. K., and J. Thigpen. 1996. A social exchange explanation of participation in the U.S. Farm Program. South. Rural Sociol. 12:1-23.

Vandermersch, M., and E. Mathijs. 2004. The impact of management attitudes on financial performance of Flemish dairy farms. J. Farm Manag. 11:637-648.

Visser, C.F. 2013. Professional helpers' growth mindset, work engagement and self-reported performance. Accessed Mar. 2, 2014. http:/ /progressfocusedapproach.com/uploads/Visser2013-2.pdf.

Wilson, P. D. Hadley, and C. Asby. 2001. The influence of management characteristics on the technical efficiency of wheat farmers in eastern England. Agric. Econ. 24:329-338.

Wilson, P., M. Lewis, R. Crane, P. Robertson, J. Bonner, R. Davenport, and M. Riley. 2012. Farm level performance: Identifying common factors determining levels of performance. Rural Business Research, Nottingham, UK.

\section{APPENDIX}

Table A1. Illustration of accounts summary showing how profit before resource costs and profit are calculated (prices as of Dec. 31 , $2013 ; £ 1=\$ 1.65$ )

\begin{tabular}{lr}
\hline Item & Price $(£)$ \\
\hline Business turnover & $\mathbf{6 4 2 , 1 4 8}$ \\
Livestock & 608,856 \\
Crops & 6,250 \\
Forage & 380 \\
Commercial & 0 \\
Sundry & 26,662 \\
Less variable costs & $\mathbf{2 3 3 , \mathbf { 1 6 5 }}$ \\
Livestock & 190,726 \\
Crops & 4,785 \\
Forage & 37,654 \\
Commercial & 0 \\
Sundry & 0 \\
Equals business gross margin & $\mathbf{4 0 8 , 9 8 3}$ \\
Livestock & 418,130 \\
Crops & 1,465 \\
Forage & $-37,274$ \\
Commercial & 0 \\
Sundry & 26,662 \\
Less direct overhead costs & $\mathbf{1 9 5 , 7 9 0}$ \\
Wages & 51,136 \\
Power and machinery & 93,366 \\
Administration & 23,241 \\
Property charges & 28,047 \\
Equals profit before resource costs & $\mathbf{2 1 3 , 1 9 3}$ \\
Less total resource costs (including depreciation) & $\mathbf{6 9 , 1 9 8}$ \\
Land rent & 10,975 \\
Quota leasing & 0 \\
Machinery, fixtures investment depreciation & 37,016 \\
Finance charges (including interest and charges) & 21,207 \\
Equals profit & $\mathbf{1 4 3 , 9 9 5}$ \\
\hline
\end{tabular}

